\title{
Mouse limb deformity mutations disrupt a global control region within the large regulatory landscape required for Gremlin expression
}

\author{
Aimée Zuniga, ${ }^{1,2}$ Odyssé Michos, ${ }^{1,2}$ François Spitz, ${ }^{3}$ Anna-Pavlina G. Haramis, ${ }^{4,5}$ Lia Panman, ${ }^{2}$ \\ Antonella Galli, ${ }^{1}$ Kristina Vintersten, ${ }^{4,6}$ Christian Klasen, ${ }^{4}$ William Mansfield, ${ }^{4}$ Sylwia Kuc, ${ }^{2}$ \\ Denis Duboule, ${ }^{3}$ Rosanna Dono, ${ }^{2,7}$ and Rolf Zeller ${ }^{1,8}$ \\ ${ }^{1}$ Developmental Genetics, Department of Clinical-Biological Sciences, University of Basel Medical School, CH-4056 Basel, \\ Switzerland; ${ }^{2}$ Department of Developmental Biology, Utrecht University, NL-3584CH Utrecht, The Netherlands; \\ ${ }^{3}$ Department of Zoology and Animal Biology, National Center of Competence in Research 'Frontiers in Genetics' University \\ of Geneva, CH-1211 Geneva, Switzerland; ${ }^{4}$ European Molecular Biology Laboratory, D-69117 Heidelberg, Germany
}

The mouse limb deformity (Id) mutations cause limb malformations by disrupting epithelial-mesenchymal signaling between the polarizing region and the apical ectodermal ridge. Formin was proposed as the relevant gene because three of the five $1 d$ alleles disrupt its C-terminal domain. In contrast, our studies establish that the two other $1 d$ alleles directly disrupt the neighboring Gremlin gene, corroborating the requirement of this BMP antagonist for limb morphogenesis. Further doubts concerning an involvement of Formin in the $1 d$ limb phenotype are cast, as a targeted mutation removing the C-terminal Formin domain by frame shift does not affect embryogenesis. In contrast, the deletion of the corresponding genomic region reproduces the $1 d$ limb phenotype and is allelic to mutations in Gremlin. We resolve these conflicting results by identifying a cis-regulatory region within the deletion that is required for Gremlin activation in the limb bud mesenchyme. This distant cis-regulatory region within Formin is also altered by three of the $1 d$ mutations. Therefore, the $1 d$ limb bud patterning defects are not caused by disruption of Formin, but by alteration of a global control region (GCR) required for Gremlin transcription. Our studies reveal the large genomic landscape harboring this GCR, which is required for tissue-specific coexpression of two structurally and functionally unrelated genes.

[Keywords: cis regulation; Formin; global control region; Gremlin; limb development; regulatory landscape]

Supplemental material is available at http://www.genesdev.org.

Received February 8, 2004; revised version accepted May 5, 2004.

The mouse is the genetic model of choice to study mammalian development and disease. In addition to alteration of specific genes by gene targeting and transgenesis, mutant mouse strains identified by phenotypic screens are commonly used to analyze developmental and disease processes (for reviews, see Justice 2000; Perkins 2002). A significant fraction of spontaneous mutations in mice (and humans) cause congenital limb malformations and have proven crucial to unravel the mo-

Present addresses: ${ }^{5}$ Hubrecht Laboratorium, NL-3584 CT Utrecht, The Netherlands; ${ }^{6}$ Mount Sinai Hospital, Samuel Lunenfeld Research Institute, Stem Cell Mutagenesis Laboratory, Toronto, Ontario M5G 1X5, Canada; ${ }^{7}$ Development and Pathology of the Nervous System, Institut de Biologie du Développement de Marseille Campus de Luminy, Case 907, F-13288 Marseille CEDEX 09, France.

${ }^{8}$ Corresponding author.

E-MAIL Rolf.Zeller@unibas.ch; FAX 41-16-267-3959.

Article published online ahead of print. Article and publication date are at http://www.genesdev.org/cgi/doi/10.1101/gad.299904. lecular mechanisms regulating vertebrate limb bud morphogenesis (for review, see Gurrieri et al. 2002). In particular, several alleles of the recessive mouse $\operatorname{limb}$ deformity (ld) mutation disrupt patterning of the distal limb skeleton. Over the years, a total of five $1 d$ alleles have been identified by phenotypic and genetic complementation analysis. All ld homozygous newborn mice display limb patterning defects characterized by synostosis of the zeugopod in combination with oligo- and syndactyly of metacarpal bones and digits (for review, see Zeller et al. 1999). In addition, ld homozygous newborn mice display varying degrees of uni- and bilateral renal aplasias depending on allele "strength" (Maas et al. 1994). Molecular analysis showed that the two $1 d$ alleles $\left(1 d^{\mathrm{TgHd}}, l d^{\mathrm{TgBri}}\right)$ that arose by chance insertional mutagenesis disrupt the C-terminal region of the Formin gene (for details, see Wang et al. 1997). The $1 d^{\mathrm{In} 2}$ allele arose by an $\sim 40-\mathrm{Mb}$ inversion with breakpoints in the C-ter- 
minal region of Formin and the Agouti locus (Maas et al. 1990; Woychik et al. 1990). To date the molecular lesions in the two first identified $l d$ alleles, $1 d^{\mathrm{OR}}$ and $1 d^{\mathrm{J}}$ (for review, see Zeller et al. 1999), remained obscure as there are no alterations in the Formin open reading frame (ORF; Wynshaw-Boris et al. 1997). Formin (or Formin-1) is the founding member of a multigene family that mediates cytoskeletal rearrangements in response to signals that induce, for example, cell polarization (for review, see Evangelista et al. 2003). The Formin proteins are encoded by at least 24 exons spread over $\sim 400 \mathrm{~kb}$, and alternative splicing gives rise to several protein isoforms of $\sim 180 \mathrm{kDa}$. All Formin isoforms share a proline-rich FH1 domain (interacting with SH3 domains and Profilin) and a highly conserved C-terminal FH2 domain, which is required to stimulate polymerization of linear actin filaments (for reviews, see Zeller et al. 1999; Kobielak et al. 2004). However, inactivation of specific Formin isoforms by gene targeting in the mouse resulted in partial renal agenesis phenotypes, but failed to reproduce the $1 d$ limb phenotype as limb morphogenesis was normal (Wynshaw-Boris et al. 1997; Chao et al. 1998).

In $1 d$ homozygous embryos, the epithelial-mesenchymal signaling interactions regulating limb bud development are disrupted (for review, see Panman and Zeller 2003). Limb bud growth and patterning are coordinately controlled by two main signaling centers, the Sonic hedgehog (Shh)-expressing polarizing region, located in the posterior limb bud mesenchyme and the apical ectodermal ridge (AER), which expresses several types of signals including Fibroblast growths factors (Fgfs) and Bone morphogenetic proteins (Bmps). Molecular analysis of $1 d$ mutant limb buds revealed that activation of Fgf4 expression in the posterior AER, establishment of the SHH/FGF4 feedback loop, and thereby up-regulation of Shh expression by the polarizing region are disrupted (for review, see Panman and Zeller 2003). A functional screen for mesenchymal signals able to relay SHH to the AER resulted in identification of the BMP antagonist Gremlin as the signal lacking from $l d$ mutant limb bud mesenchyme. Grafts of Gremlin-expressing cells into ld mutant limb buds restore $\mathrm{Fgf4}$ expression and the $\mathrm{SHH} /$ FGF4 feedback loop (Zuniga et al. 1999). Analysis of Gremlin-deficient mouse embryos generated by gene targeting has confirmed its essential functions during limb bud development (Khokha et al. 2003; Michos et al. 2004). Induction of Fgf8-expressing AER cells occurs normally, but a morphologically distinct and functional AER fails to form in Gremlin-deficient embryos. Gremlin-mediated BMP antagonism is required in the limb bud mesenchyme to enable expression of various types of AER signals such as Fgfs and Bmps and for survival of core mesenchymal cells (Michos et al. 2004). The general disruption of AER function in Gremlin-deficient embryos in turn blocks propagation of Shh expression by the polarizing region as is also observed in $l d$ mutant limb buds. In addition, the induction of metanephric kidney organogenesis and complete differentiation of lung airway epithelia fail to occur, which causes neonatal lethality. The studies by Michos et al. (2004) reveal a more general role of Gremlin-mediated BMP antagonism in epithelial-mesenchymal signaling during vertebrate organogenesis. Interestingly, the Gremlin transcription unit maps only $\sim 40 \mathrm{~kb}$ downstream from the Formin gene on mouse chromosome 2 and is transcribed in opposite orientation (University of California at Santa Cruz Genome Browser, http://genome.ucsc.edu). Finally, Khokha et al. (2003) established allelism between one of the $1 d$ alleles $\left(1 d^{\mathrm{J}}\right)$ and a Gremlin null allele generated by gene targeting, but did not analyze the genetic and molecular basis for these rather unexpected findings.

In the present study we establish that the $1 d^{\mathrm{J}}$ mutation is a point mutation affecting splicing of Gremlin transcripts that results in truncation of the $5^{\prime}$ part of the Gremlin ORF. Furthermore, the complete Gremlin ORF encoded by exon 2 is deleted by the $1 d^{\mathrm{OR}}$ mutation. Therefore, these two $1 d$ alleles are spontaneous Gremlin loss-of-function alleles, which also establishes that the ld complementation group encompasses both the Gremlin and Formin loci. Using gene targeting we show that disruption of the Formin FH2 domain by deleting coding exon $10\left(F m n^{\Delta 10}\right.$ mutation) does not reproduce the $1 d$ phenotype. In contrast, deletion of the genomic region encompassing exons $10-24\left(F m n^{\Delta 10.24}\right.$ mutation) results in the characteristic $l d$ limb phenotype. Interestingly, the Fmn ${ }^{\Delta 10.24}$ deletion, but not the Fmn ${ }^{\Delta 10}$ mutation, is allelic to Gremlin loss-of-function mutations. Further analysis establishes that the deleted region encodes regulatory elements required to activate both Formin and Gremlin expression in the posterior limb bud mesenchyme and mediate responsiveness to $\mathrm{SHH}$, but not to FGF signaling. BAC transgenic analysis positively identifies this cis-regulatory region and shows that it is required to activate Gremlin transcription in the posterior-distal limb bud mesenchyme. The features of this large cis-regulatory landscape are reminiscent of a recently discovered global control region, a novel type of chromosomal regulatory element that controls expression of 5'Hoxd genes in the distal limb bud mesenchyme (Spitz et al. 2003). Taken together, our studies establish that the $1 d$ limb phenotype is a direct consequence of losing Gremlin expression in the limb bud mesenchyme and not due to disrupting Formin functions. We also discuss how such large regulatory landscapes that control tissue-specific coexpression of functionally unrelated genes may have arisen.

\section{Results}

The $1 \mathrm{~d}^{\mathrm{J}}$ and $\mathrm{ld}^{\mathrm{OR}}$ alleles are loss-of-function mutations directly disrupting the Gremlin gene products

In contrast to the three independent alleles of the mouse ld mutation that truncate Formin (see the introduction), no molecular alterations of the Formin ORF were identified for the $1 d^{\mathrm{OR}}$ and $1 d^{\mathrm{J}}$ alleles (Wynshaw-Boris et al. 1997). However, both these $1 d$ mutations are allelic to null mutations in the neighboring Gremlin gene (generated by gene targeting; Michos et al. 2004) as compound heterozygous mice display the characteristic $1 d$ limb 
phenotype (Fig. 1A; Khokha et al. 2003). Furthermore, newborn $1 d^{\mathrm{OR}}$ homozygous mice lack kidneys and ureters (Supplementary Fig. 1) similar to Gremlin-deficient and $l d^{\mathrm{J}}$ homozygous mice (Maas et al. 1994). This renal agenesis in combination with lung defects (Supplementary Fig. 1) causes death shortly after birth identical to Gremlin null mutant mice (Michos et al. 2004). Molecular analysis of the $1 d^{\mathrm{OR}}$ allele indeed reveals a $12.7-\mathrm{kb}$ genomic deletion removing the complete Gremlin ORF (Fig. $1 \mathrm{~B}, \mathrm{C}$ ), which establishes the $1 d^{\mathrm{OR}}$ mutation as a spontaneous Gremlin null allele. In sharp contrast, Gremlin transcripts remain expressed in embryos homozygous for the $1 d^{\mathrm{J}}$ allele (Fig. 1D), despite the fact that activation of $\mathrm{FgfA}$ in the posterior AER is disrupted and the Shh expressing polarizing region is not maintained (Haramis et al. 1995). Sequence analysis of the Gremlin locus in the $1 d^{\mathrm{J}}$ allele reveals a specific G-to-A base change at the first intron-exon 2 boundary (asterisk in Fig. 1E). This point mutation eliminates the intronic AG motif at the $3^{\prime}$ splice site, which is essential for correct pre-mRNA splicing (Faustino and Cooper 2003). Indeed, a single aberrantly spliced transcript with a 65-base deletion removing the $5^{\prime}$ part of exon 2 was identified in $1 d^{\mathrm{J}}$ homozygous embryos (Fig. 1F; data not shown). This aberrant splice makes use of a downstream AG dinucleotide within exon 2 that is preceded by a pyrimidinerich stretch required for splicing (Fig. 1F; Faustino and Cooper 2003). This deletion within the Gremlin transcript removes the AUG translational start codon, thereby abolishing translation of full-length secreted Gremlin protein (Fig. 1F).

Not the disruption of the Formin FH2 domain, but deletion of the corresponding genomic region causes the ld limb phenotype

The fact that the $1 d^{\mathrm{OR}}$ and $1 d^{\mathrm{J}}$ alleles are Gremlin lossof-function mutations (Fig. 1) reiterates the question of whether the disruption of Formin functions is indeed the primary cause of the $l d$ phenotype. In particular, the Gremlin gene is located $\sim 40 \mathrm{~kb}$ downstream from Formin and transcribed in opposite orientation, extending the $l d$ complementation group to $\sim 450-500 \mathrm{~kb}$ in size (Fig. 2A). Previous analysis showed that the other three $l d$ alleles $\left(l d^{\mathrm{In} 2}, l d^{\mathrm{TgBri}}\right.$, and $l d^{\mathrm{TgHd}}$; for details, see Wang et al. 1997) disrupt the genomic region encoding the Cterminal part of Formin (encoded by exons 10-24; Fig. $2 \mathrm{~A})$. In an attempt to reproduce the $1 d$ phenotype and possibly generate a null allele by reverse genetics, Formin exon 10 was deleted $\left(F m n^{\Delta 10}\right.$ allele; Fig. $2 B$; for details, see Materials and Methods). Exon 10 was chosen as its deletion results in a frame shift that disrupts translation of the C-terminal protein domain completely (Fig. 2E). Rather unexpectedly, $F m n^{\Delta 10}$ homozygous mice are phenotypically wild type (Fig. 2C; data not shown), thereby establishing that deletion of exon 10 is not sufficient to reproduce the $l d$ phenotype. Next, we deleted the complete genomic region spanning exons 10-24 (Fig.
A

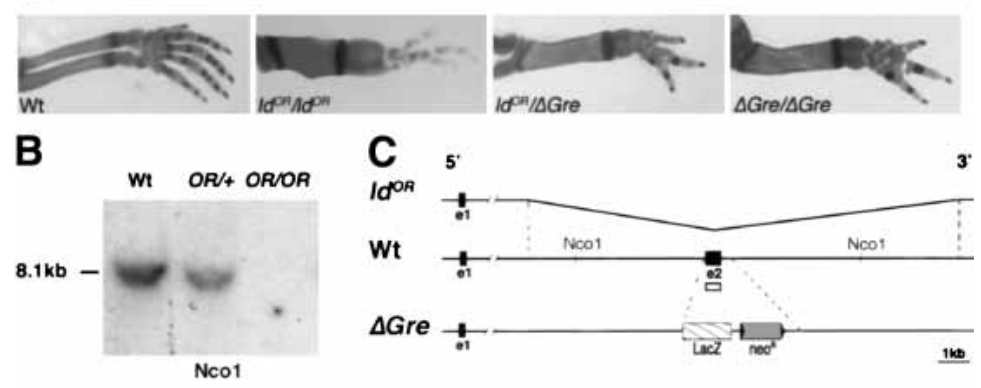

D

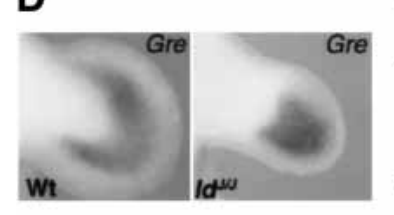

E
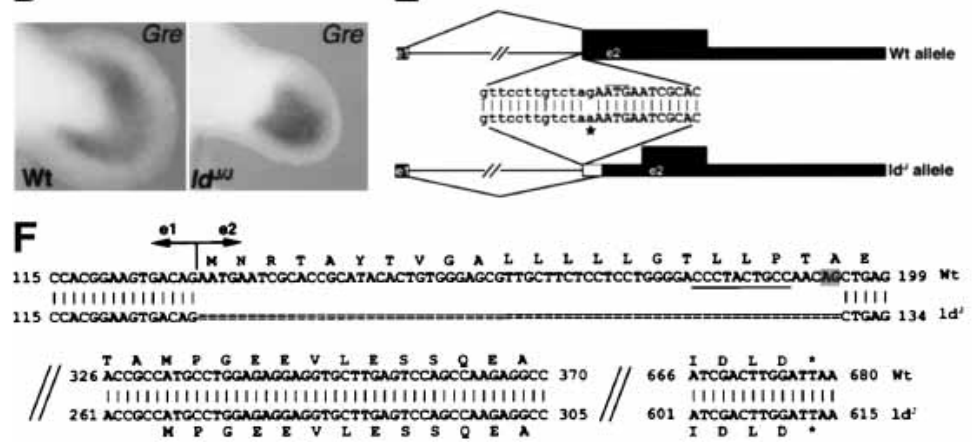

Figure 1. The $l d^{\mathrm{OR}}$ and $l d^{\mathrm{J}}$ mutations are Gremlin lossof-function alleles. $(A)$ The $1 d^{\mathrm{OR}}$ mutation is allelic to a Gremlin null allele $(\Delta G r e)$ generated by gene targeting (Michos et al. 2004). (B) Southern blot analysis reveals that the Gremlin ORF encoded by exon 2 is deleted in the $1 d^{\mathrm{OR}}$ mutation. Genomic DNA isolated from embryos was digested by Ncol and probed with a Gremlin exon 2 probe (open box in scheme, C). (Wt) Wild-type littermate; $(O R /+)$ heterozygous embryo; $(O R / O R)$ homozygous embryo. $(C)$ Schematic representation of the Gremlin locus on chromosome 2 in the $1 d^{\mathrm{OR}}$ allele, wild-type, and $\Delta$ Gre mutation. (ld $\left.{ }^{\mathrm{OR}}\right)$ Kinked line indicates the $12.7-\mathrm{kb}$ region deleted in the $1 d^{\mathrm{OR}}$ mutation. $(\mathrm{Wt})$ Open box indicates the probe used for the Southern blot analysis shown in $B .(\Delta G r e) L a c Z$ and the $N e o^{\mathrm{R}}$ replace coding exon 2 in the Gremlin null allele generated by gene targeting. (e1) Exon 1 ; (e2) exon 2. (D) Gremlin remains expressed in $1 d^{\mathrm{J}}$ homozygous embryos. Shown are limb buds of a wild-type $(\mathrm{Wt})$ and $l d^{\mathrm{J}}$ homozygous $\left(1 d^{\mathrm{J} / \mathrm{T}}\right)$ mouse embryo at E11.5. (E) The G-to-A mutation at the intron-exon 2 junction of the Gremlin gene in the $1 d^{\mathrm{J}}$ allele (indicated by an asterisk) disrupts splicing. Lowercase indicate intronic, uppercase indicate exonic sequences. Thick black boxes indicate the Gremlin ORF, thin boxes indicate the $5^{\prime}$ and $3^{\prime}$ noncoding regions. The thin white box indicates the deletion of mRNA due to aberrant splicing. Thin black lines indicate intronic sequences and splices. $(F)$ Aberrant pre-mRNA splicing deletes the first 65 bases of the Gremlin ORF. Shown is an alignment of the cDNA sequences of wild-type $(\mathrm{Wt})$ and $l d^{\mathrm{J}}$ alleles with the respective ORFs. The truncated $l d^{\mathrm{J}}$ Gremlin transcript could potentially encode a Gremlin protein of 117 amino acids (instead of 184) lacking the signal peptide (Avsian-Kretchmer and Hsueh 2003). The AG dinucleotide used for splicing in the $1 d^{\mathrm{J}}$ allele is shaded gray. The required upstream poly-pyrimidine tract is underlined (Faustino and Cooper 2003). 
Figure 2. Not disruption of the Formin $\mathrm{FH} 2$ domain, but deletion of the corresponding genomic region causes the $1 d$ limb phenotype. (A) Schematic representation of the $1 d$ complementation group consisting of Formin and Gremlin loci. The Formin gene is encoded by at least 24 exons (transcriptional direction indicated by arrow; Wang et al. 1997), whereas the Gre gene is transcribed in reverse orientation (bold arrow) and contains only two exons. The intergenic region separating the two genes is $\sim 38 \mathrm{~kb}$. The Formin FH2 domain is encoded by exons 10-24 and is present in all Formin protein isoforms (Wang et al. 1997). The following genetically engineered mutations are indicated: $(\Delta 10)$ $F m n^{\Delta 10}$ allele; $(\Delta 10.24) F m n^{\Delta 10.24}$ allele; $\left(\Delta\right.$ Gre) Gre $e^{\Delta \mathrm{ORF}}$ null allele (Michos et al. 2004). The spontaneous $l d$ alleles are indicated: $\left(1 d^{\mathrm{TgBri}}\right)$ transgene induced deletion of genomic region between exons 19 and 23 (Vogt et al. 1992); (ld $\left.{ }^{\mathrm{TgHd}}\right)$ transgene insertional mutagenesis (Woychik et al. 1985); $\left(1 d^{\operatorname{In} 2}\right)$ 40-Mb inversion involving Formin and Agouti loci (Woychik et al. 1990); $\left(1 d^{\mathrm{OR}}\right)$ deletion of the Gre ORF; $\left(1 d^{\mathrm{J}}\right)$ point mutation disrupting Gre pre-mRNA splicing. (B) Schematic representation of the genetically engineered $F m n^{\Delta 10}$ and $F m n^{\Delta 10.24}$ alleles. (Neo) PGK-Neo ${ }^{\mathrm{R}}$ gene used to select ES-cell clones (first round of gene targeting); (Hygro) PGK-Hygro ${ }^{\mathrm{R}}$ gene used to select ES-cell clones (second round of gene targeting); (lacZ) IRES-LacZ gene used to tag Fmn transcripts. Arrows indicate direction of transcription. Formin exons are numbered as in $A$. (C, left panels) Limb skeletal phenotypes of wild-type and homozygous mice. Genotypes are indicated in the panels. (Right panels) Gremlin expression in limb buds of wild-type and homozygous embryos (E10.75). For nomenclature see the legend for $A$. (D) RT-PCR of Formin transcripts isolated from wild-type $(\mathrm{Wt}), F m n^{\Delta 10}(\Delta 10)$ and $F m n^{\Delta 10.24}(\Delta 10.24)$ homozygous embryos. Wild-type and $F m n^{\Delta 10}$ mRNAs extending downstream from exon 9 were detected using primers in exons 9 and 23, $F m n^{\Delta 10.24}$ mRNAs extending downstream from exon 9 were detected using primers in exon 9 and the IRES-LacZ tag (see Materials and Methods). (+) Reverse transcriptase included; $(-)$ reverse transcriptase omitted (control). Note that the difference in size between wild-type (Wt) and $F m n^{\Delta 10}$ transcripts is 150 bases, as expected. (E) Amino acid sequence deduced from the sequences of the Formin transcripts arising from wild-type, Fmn ${ }^{\Delta 10}$ and $F m n^{\Delta 10.24}$ alleles.

$2 \mathrm{~A}$; region 10.24), which results in the $F m n^{\Delta 10.24}$ allele (Fig. 2B; for details, see Materials and Methods). Mice homozygous for the $F m n^{\Delta 10.24}$ allele indeed display the characteristic $1 d$ limb phenotype (Fig. 2C). However, $F n^{\Delta 10.24}$ homozygous newborn mice display neither renal agenesis nor lung patterning phenotypes and survive to adulthood (data not shown). Molecular analysis of $F m n^{\Delta 10.24}$ homozygous embryos reveals that Gremlin expression is lost specifically from the limb bud mesenchyme, whereas it is normal in Fmn ${ }^{\Delta 10}$ homozygous embryos (Fig. 2C; data not shown). In agreement with limb bud specific loss of Gremlin expression, activation of Fgfs in the posterior AER and SHH-GRE/AER feedback signaling are disrupted in Fmn ${ }^{\Delta 10.24}$ homozygous embryos (Supplementary Fig. 2), but not in Fmn ${ }^{\Delta 10}$ homozygous embryos (data not shown). One possible explanation for the lack of an $1 d$ limb phenotype in $F m n^{\Delta 10}$ homozygous embryos could be the rescue of Formin function due to aberrant splicing. However, thorough analysis of Formin transcripts extending $3^{\prime}$ to exon 9 by RT-PCR provided no evidence for aberrant splicing (Fig. 2D; data not shown). Furthermore, sequence analysis of the altered Formin transcripts in Fmn ${ }^{\Delta 10}$ and Fmn ${ }^{\Delta 10.24}$ homozygous embryos establishes that the Formin ORF is truncated in both alleles at the level of the exon 9/10 boundary (Fig. 2E). These results show that the $l d$ limb 
phenotype in the Fmn ${ }^{\Delta 10.24}$ mutation is not caused by disruption of the C-terminal Formin protein domain as previously concluded (for review, see Zeller et al. 1999), but by the deletion of other essential elements located in the genomic region 10.24 .

The genomic region 10.24 exerts cis-effects on Gremlin expression in the limb bud mesenchyme

The phenotypic analysis indicated that all $l d$ mutations belong to the same complementation group in spite of their disrupting either the Formin or Gremlin loci (Fig. 2A); therefore, allelism between the $F m n^{\Delta 10}, F m n^{\Delta 10.24}$, and $G r e^{\Delta \mathrm{ORF}}$ mutations was assessed. Limbs of $F m n^{\Delta 10 / \Delta 10.24}$ and $F m n^{\Delta 10} ; G r e^{\Delta \mathrm{ORF}}$ compound heterozygous mice are normal (Fig. 3A,B), confirming the wild-type phenotypic nature of the $F m n^{\Delta 10}$ mutation. In contrast, the $F m n^{\Delta 10.24}$ mutation is a hypomorphic allele of the $G r e^{\Delta \mathrm{ORF}}$ null mutation as $F \mathrm{mn}^{\Delta 10.24 /{ }^{+}}$; Gre $\mathrm{CORF}^{\Delta \mathrm{O}+}$ mice display a fully penetrant $l d$ limb phenotype (Fig. 3C), but not the phenotypes causing neonatal lethality (data not

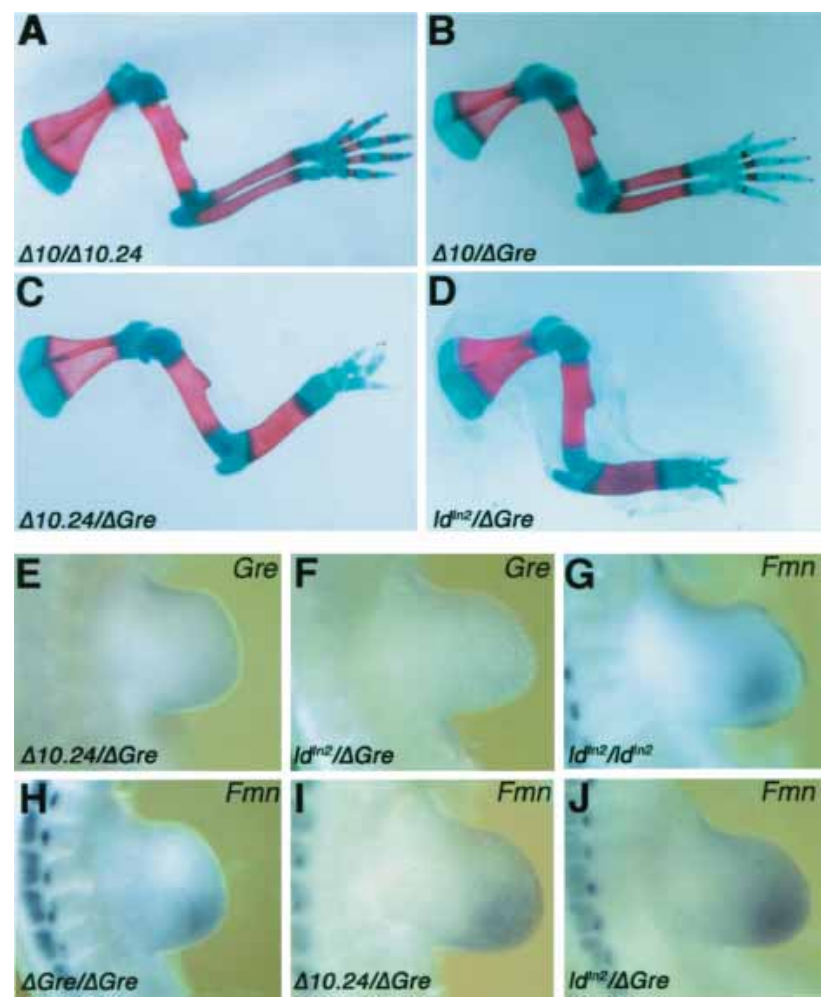

Figure 3. The $F m n^{\Delta 10.24}$ and $l d^{\operatorname{In} 2}$ mutations are allelic to $G r e^{\Delta \mathrm{ORF}}$ by disrupting cis regulation of Gremlin in the limb bud mesenchyme. $(A-D)$ Forelimb skeletal phenotypes of compound heterozygous mice. $(E, F)$ Gremlin is no longer expressed in the limb bud mesenchyme of $\mathrm{Fmn}^{\Delta 10.24 /+}$; Gre $\mathrm{GORF}^{\Delta \mathrm{+}}(E)$ and $1 \mathrm{~d}^{\mathrm{In} 2 /+}$; $G r e^{\Delta \mathrm{ORF} /+}(F)$ compound heterozygous embryos. $(G-J)$ Formin remains expressed in the limb bud mesenchyme of $1 d^{\operatorname{In} 2 / \operatorname{In} 2}$ $(G), G r e^{\Delta \mathrm{ORF} / \Delta \mathrm{ORF}}(H), \mathrm{Fmn}^{\Delta 10.24 /+} ; G r e^{\Delta \mathrm{ORF} /+}(I)$, and $1 d^{\mathrm{In} 2 /+}$; $G r e^{\Delta \mathrm{ORF} /+}(J)$ compound heterozygous embryos. Note: Samples $G-J$ were pretreated prior to whole mount in situ hybridization for optimal detection of Formin transcripts in the mesenchyme. Such pretreatment results in loss of the AER. Genotypes are indicated as defined in the legend for Figure 2A. shown). The $l d^{\operatorname{In} 2}$ allele is of particular interest, as an inversion between Formin and Agouti (Woychik et al. 1990 ) relocates the Gremlin gene $\sim 40 \mathrm{Mb}$ away on mouse chromosome 2. Compound $1 d^{\operatorname{In} 2 /+} ; G r e^{\Delta \mathrm{ORF} /+}$ heterozygous mice also display the $1 d$ limb phenotype (Fig. 3D), which indicates that integrity of the genomic region encoding Formin and Gremlin (Fig. 2A) is required in cis for normal limb bud development. Therefore, the loss of Gremlin expression in Fmn ${ }^{\Delta 10.24}$ (Fig. 2E) and $1 d^{\operatorname{In} 2}$ homozygous limb buds seems to be a consequence of either deleting $\left(F m n^{\Delta 10.24}\right)$ or disrupting $\left(l d^{\operatorname{In} 2}\right)$ a distant cisregulatory element of Gremlin expression in limb buds rather than disrupting Formin functions (Zuniga et al. 1999). Indeed, Gremlin transcription is lost from the limb bud mesenchyme of $F m n^{\Delta 10.24} ; G r e^{\Delta \mathrm{ORF}}$ and $1 d^{\operatorname{In} 2}$; $G r e^{\Delta \mathrm{ORF}}$ compound heterozygous embryos (Fig. 3E,F). Conversely, Formin remains expressed in limb buds of $1 d^{\ln 2}$ and Gre $e^{\Delta \mathrm{ORF}}$ homozygous (Fig. 3G,H) and compound heterozygous embryos (Fig. 3I,J). These results indicate that the relevant elements in question are located upstream of Formin coding exon 23. As no additional genes have been found in the genomic region 10.24 (data not shown), these results indicate that this region is required for cis regulation of Gremlin expression in the limb bud mesenchyme.

\section{Cis-regulatory elements in region 10.24 mediate activation and SHH responsiveness in the limb bud mesenchyme}

To explore the molecular mechanism for cis regulation of Gremlin, we analyzed the expression of exogenous genes inserted into the $1 d$ locus (Fig. 2A,B). In the Fmn ${ }^{\Delta 10}$ and $F m n^{\Delta 10.24}$ alleles, expression of the $L a c Z$ reporter gene is controlled by the endogenous Fmn promoters (Fig. 2B). As a consequence, the LacZ distribution recapitulates Formin expression perfectly in $F \mathrm{Fn}^{\Delta 10}$ heterozygous embryos (Fig. 4, cf. A and B). In Fmn ${ }^{\Delta 10.24}$ heterozygous embryos, $L a c Z$ activity (Fig. 4C) is specifically lost from the limb bud mesenchyme (arrowheads in Fig. 4, cf. D,E and F). These results reveal that the genomic region 10.24 is required for limb bud mesenchymal expression of both Gremlin and Formin (Figs. 3E, 4C,F). Furthermore, insertion of PGK promoters driving expression of $\mathrm{NeO}^{\mathrm{R}}$ and $\mathrm{Hygro}^{\mathrm{R}}$ genes at various positions (Fig. 2B) results in these exogenous transcripts being expressed like Formin and Gremlin in the limb bud mesenchyme (Fig. 4G-I), irrespective of transgene insertion site and orientation (Fig. 2B). In contrast, expression of the $\mathrm{NeO}^{\mathrm{R}}$ transgene is lost in limb buds heterozygous for the Fmn ${ }^{\Delta 10.24}$ mutation (Fig. 4J). These results reveal the presence of cis-regulatory elements within Fmn genomic region 10.24 able to drive expression of exogenous genes in the limb bud mesenchyme. As both Gremlin and Formin expression are positively regulated by $\mathrm{SHH}$ signaling in the limb bud mesenchyme (Zuniga et al. 1999), a potential role of region 10.24 in mediating this $\mathrm{SHH}$ responsiveness was assessed. Indeed, anterior grafts of $\mathrm{SHH}$ expressing cells induce ectopic LacZ expression in cultured limb buds of $F m n^{\Delta 10}$ heterozygous embryos 
Figure 4. The Formin genomic region 10.24 regulates expression of endogenous and exogenous transcription units inserted into the $1 d$ locus. $(A)$ Formin transcript distribution in a wild-type embryo around gestational day 10.5 (hemisection). (B) LacZ recapitulates the Formin transcript distribution in the $F m n^{\Delta 10}$ allele. $(C)$ Limb bud mesenchymal $\mathrm{LacZ}$ is specifically lost in the $F m n^{\Delta 10.24}$ allele. (DF) Forelimb buds of the embryos shown in $A-C$. Black arrowheads indicate $\mathrm{Fmn} / \mathrm{LacZ}$ distribution in the mesenchyme and open arrowhead indicates the loss of $L a c Z$ in the Fmn ${ }^{\Delta 10.24}$ allele. $(G-J)$ Limb bud mesenchyme-specific expression of the Hygro $^{\mathrm{R}}$ $(G)$ and $\mathrm{NeO}^{\mathrm{R}}(\mathrm{H}-J)$ genes inserted into the $\mathrm{ld}$ locus. Genotypes are indicated as defined in the legend for Figure 2A.

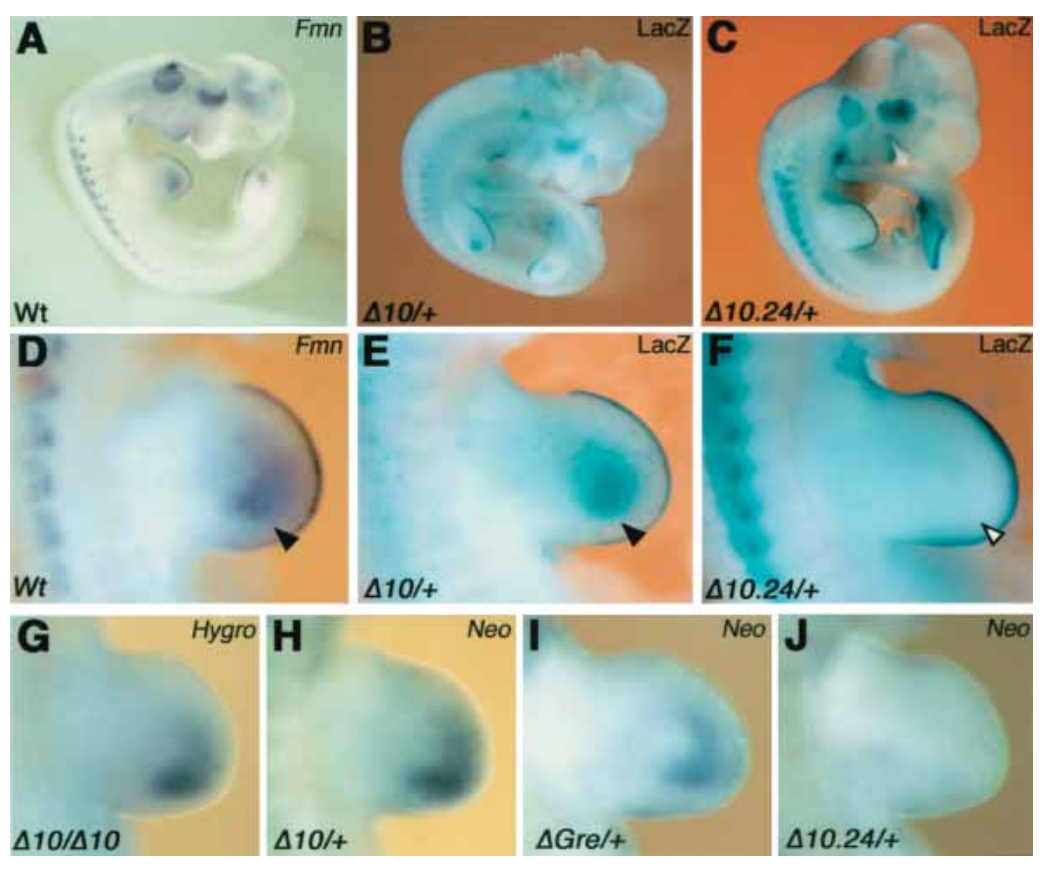

(Fig. 5, cf. A and B). In contrast, SHH is unable to induce LacZ expression in limb buds of $F m n^{\Delta 10.24}$ heterozygous embryos (Fig. 5, cf. C and D), which indicates that this region participates in mediating SHH responsiveness of Formin and Gremlin in the limb bud mesenchyme. In contrast to the Fmn ${ }^{\Delta 10.24}$ allele (Fig. 5D), Formin but not Gremlin (Zuniga et al. 1999) expression can be ectopically induced by SHH in $1 d^{\ln 2}$ homozygous limb buds (Fig. 5, cf. E and F; data not shown). These results show that the inversion affecting the $1 d^{\operatorname{In} 2}$ allele separates the Gremlin, but not Formin transcription unit from the SHH response elements (see also Fig. 7A, below).

Analysis of Gremlin expression in chicken embryos suggested that its expression in the limb bud mesenchyme may depend on FGF signaling by the AER (Merino et al. 1999). However, limb buds of $F m n^{\Delta 10 / \Delta 10} \mathrm{em}$ bryos cultured in the presence the FGF signaling inhibitor SU5402 (Mohammadi et al. 1997; for details, see Materials and Methods) continue to express $\mathrm{LacZ}$ and Gremlin (Fig. 5, cf. G,I and H,J). As expected, inhibition of FGF signaling causes flattening of the AER (data not shown) and subsequent down-regulation of Shh and Fgf expression due to disrupting feedback signaling (Fig. $5 \mathrm{~K}, \mathrm{~L}$; data not shown). The results shown in Figure 5G-J indicate that mesenchymal Formin and Gremlin expression does not depend significantly on FGF signaling. In agreement, genetic analysis reveals that Gremlin, but not Shh, remains expressed in mouse limb buds lacking both Fgf8 and Fgf4 (Sun et al. 2002).

The genomic region 19.23 is sufficient to activate gene expression in the limb bud mesenchyme

Using a BAC-based strategy to generate transient transgenic mouse embryos, we have positively identified the relevant cis-regulatory region (Fig. 6). Initially, a BAC containing the mouse Fmn genomic region spanning exons 19-24, the intergenic region, and the complete Gremlin transcription unit (tagged by LacZ in exon 2) was injected into fertilized oocytes and embryos stained for LacZ activity during gestational days 10.5 (Fig. 6A). This transgene (BAC construct $\mathrm{A}$ ) is expressed in the posterior limb bud mesenchyme (arrowheads in Fig. 6A, $n=5 / 6)$, which indicates that all the required cis-regulatory elements are present. In contrast, LacZ activity is specifically lost from the limb bud mesenchyme of embryos harboring $\mathrm{BAC}$ construct $\mathrm{B}$, which lacks region 19.23 (Fig. $6 \mathrm{~B}, n=7 / 7$ ). The potential autonomy of region 19.23 (Fig. 6C) was assessed by inserting it downstream from a $L a c Z$ gene under control of a minimal $\beta$-globin promoter (Morgan et al. 1996). Indeed, BAC construct C (Fig. 6C) and a shorter construct containing region 20.23 (data not shown) are sufficient to drive LacZ expression into the posterior limb bud mesenchyme (Fig. 6C, arrowheads, $n=2 / 6$ ). These results establish that region 19.23 encodes cis-regulatory elements sufficient to activate gene expression in combination with either the endogenous Gremlin or an exogenous minimal promoter (albeit with lower efficiency; Fig. 6, cf. A and C). Furthermore, region 19.23 is sufficient to activate $L a c Z$ expression in both dorsal and ventral posterior limb bud mesenchyme similar to Formin and Gremlin (Supplementary Fig. 3). Reduction of this genomic region reduces expression further, indicating that the required regulatory elements are spread over a larger region (see also Fig. 7; data not shown).

\section{Discussion}

We establish that the $1 d$ phenotype is caused by disrupting either the regulatory landscape controlling transcrip- 
tional activation of the BMP antagonist Gremlin in the limb bud mesenchyme or directly the Gremlin transcription unit. Therefore, the $1 d$ phenotype has been wrongly attributed to disruption of Formin functions. We now show that all $1 d$ alleles together with the $F m n^{\Delta 10.24}$ and $G r e^{\Delta \mathrm{ORF}}$ mutations define one allelic series of variable phenotypic strength. The $l d^{\mathrm{OR}}, l d^{\mathrm{J}}$, and $G r e^{\Delta \mathrm{ORF}}$ alleles are the strongest alleles as the Gremlin gene products are either deleted or truncated, which causes a pleiotropic loss-of-function phenotype. The complete renal agenesis and lung septation defects in $1 d^{\mathrm{OR}}$ homozygous newborn mice result in fully penetrant neonatal lethality identical to the Gre $e^{\triangle \mathrm{ORF}}$ null allele generated by gene targeting (Michos et al. 2004). A second class of $1 d$ alleles is hypomorphic $\left(\mathrm{Fmn}^{\Delta 10.24}, I d^{\mathrm{In} 2}, l d^{\mathrm{TgBri}}, l d^{\mathrm{TgHd}}\right)$. These $1 d$ alleles display the characteristic and fully penetrant $l d$ limb phenotype, but either lack or only show low frequencies of renal abnormalities and thereby generally survive to adulthood (see also Maas et al. 1994). A cis-regulatory region located within Formin that is required for Gremlin activation in the limb bud mesenchyme is either deleted or disrupted by all these hypomorphic $1 d$ alleles (Fig. 7A). Therefore, these mutations induce limb bud specific loss of Gremlin expression in cis and not in trans as a consequence of disrupting Formin (Zuniga et al. 1999). Despite the fact that $F m n^{\Delta 10}$ homozygous mice (lacking the complete C-terminal Formin domain) are normal, it cannot be excluded that other Formin protein domains function during embryonic development in pathways other than the ones disrupted due to the lack of the BMP antagonist Gremlin. In particular, specific inactivation of Formin isoform IV results in low penetrance and mostly partial renal agenesis phenotypes, whereas limbs are phenotypically wild type (WynshawBoris et al. 1997; Chao et al. 1998). The partial disruption of kidney development in these mutations and some of the hypomorphic $1 d$ alleles (see before) correlate well with abundant Formin expression during kidney morphogenesis (for review, see Zeller et al. 1999).

Our studies reveal the molecular disruption of Gremlin in the $1 d^{\mathrm{OR}}$ and $1 d^{\mathrm{J}}$ alleles and positively identify the shared limb bud cis-regulatory elements in Formin genomic region 19.23. In particular, these latter studies explain satisfactorily why disruption of Gremlin functions is the primary cause of the limb phenotypes observed in $1 d$ homozygous mice. In the $1 d^{\operatorname{In} 2}$ allele, the inversion between Formin and Agouti (Woychik et al. 1990 ) relocates the Gremlin gene $\sim 40 \mathrm{Mb}$ away from the genomic region 19.23 (Fig. 7A). The $1 d^{\mathrm{TgHd}}$ allele arose by insertion of multiple copies of a MMTV-myc transgene in combination with an $\sim 1-\mathrm{kb}$ deletion between Formin exons 19 and 20 (Woychik et al. 1985). The transgene insertion site disrupts the genomic region 19.23 and is likely to tether long-range-enhancing activity due to insertion of several strong exogenous promoters (Fig. 7A). Last but not least, the genomic region 19.23 is de-
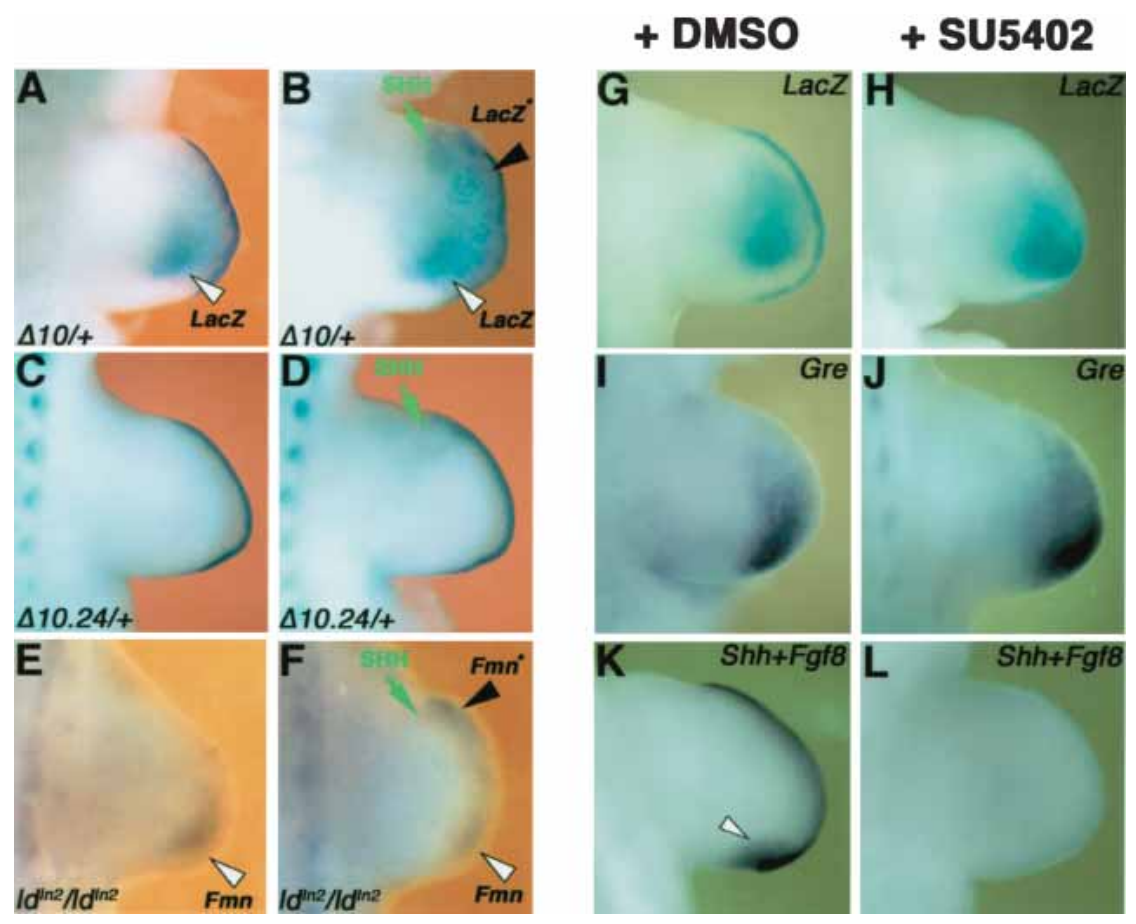

Figure 5. The limb bud regulatory region 10.24 is responsive to $\mathrm{SHH}$ signaling. $\mathrm{SHH}$ expressing cells were grafted to the anterior limb bud mesenchyme (E10.25, 32-34 somites) and trunks cultured for $16-20 \mathrm{~h}$ prior to analysis. (A) Nongrafted limb bud of an $F m n^{\Delta 10}$ heterozygous embryo (control). $(B)$ Ectopic LacZ in the contralateral limb bud having received an anterior graft of $\mathrm{SHH}$ expressing cells. $(C)$ Control Fmn ${ }^{\Delta 10.24}$ heterozygous limb bud. $(D)$ Failure to induce $\mathrm{LacZ}$ expression in response to $\mathrm{SHH}-\mathrm{ex}$ pressing cells in an Fmn ${ }^{\Delta 10.24}$ heterozygous limb bud. (E) Control limb bud of an $1 d^{\operatorname{In} 2}$ homozygous embryo. $(F)$ Induction of Fmn expression in response to ectopic SHH signaling in an $1 d^{\text {In } 2}$ homozygous embryo. In $A-F$, a green arrow indicates the position of $\mathrm{SHH}$ expressing cells, a black arrowhead and an asterisk indicate ectopic gene expression, and an open arrowhead indicates endogenous expression. $(G-L)$ Gremlin and Formin expression are maintained in $\operatorname{limb}$ buds in which FGF signaling transduction has been blocked by the inhibitor SU5402. Forelimb buds of $F m n^{\Delta 10 / \Delta 10}$ embryos (E10.0, 29-32 somites) were cultured in the presence of $10 \mu \mathrm{M}$ SU5402 (+SU5402; stock dissolved in DMSO) for 14-16 h prior to analysis. Controls were cultured in the presence of an equal concentration of DMSO (+DMSO; $0.03 \%$ final concentration in medium). (G) LacZ detection in an untreated limb bud. (H) $L a c Z$ remains in a limb bud cultured in the presence of SU5402. Note the down-regulation of LacZ in the AER due to flattening in the absence of FGF signal transduction. (I) Gremlin expression in an untreated limb bud. (J) Gremlin remains in a limb bud cultured in the presence of SU5402. (K) Detection of Shh (arrowhead) and Fgf8 transcripts (AER) in an untreated limb bud. (L) Loss of both Shh and Fgf8 expression in a limb bud cultured in the presence of SU5402. 
Zuniga et al.

A

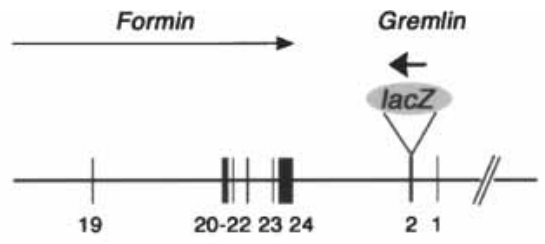

B

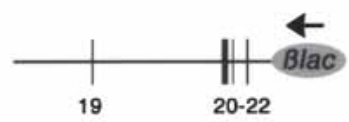

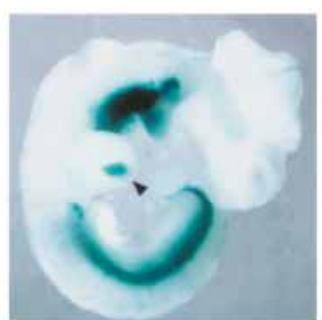
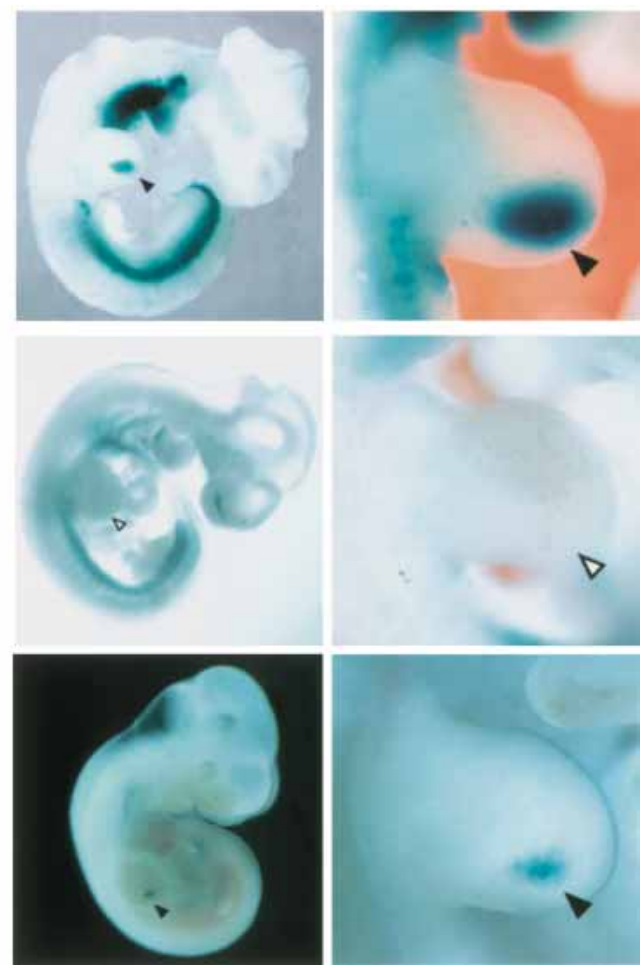

Figure 6. The Fmn locus encodes a regulatory region sufficient to activate Gremlin transcription in the limb bud mesenchyme. (A) Construct A was generated by in frame insertion of a LacZ gene 30 bases downstream from the Gremlin ATG (exon 2) into BAC \#113H17. This BAC encodes Fmn exons 19-24, the intergenic region, entire Gremlin gene and extends 150 kb upstream of Gremlin exon 1. Note that Gremlin (bold arrow) is transcribed in reverse orientation to Formin (arrow). (B) Construct B was generated by deleting the genomic region delimited by exons 19-23 from construct A. $(C)$ Construct $\mathrm{C}$ was generated by replacing Fmn exon 23 and all downstream sequences with the $\beta$-lac reporter gene in BAC \#113H17. Note that the $\beta$-lac reporter gene inserted in construct $\mathrm{C}$ is transcribed like Gremlin, that is, in reverse orientation (bold arrow) to Formin; exons are numbered as in Figure 2A. For all constructs, the LacZ distribution is shown in founder embryos around gestational day 10.5. Left panels show whole embryo views and right panels show forelimb buds. Note that different embryos are shown in the left and right panels. Black arrowheads point to the LacZ expression domains in the limb bud. Open arrowheads indicate the lack of LacZ expression in the limb bud of an embryo transgenic for construct B.

leted in the $1 d^{\text {TgBri }}$ allele (Vogt et al. 1992). We establish that such a deletion completely abolishes Gremlin activation in the posterior limb bud mesenchyme (Fig. 7A). Our results also reveal the need to reexamine the human congenital malformations mapping to the orthologous locus on chromosome 15q13-14 (Maas et al. 1991) with phenotypes similar to limb deformity. Despite the fact that mutations in the Gremlin and Formin ORF have been excluded (Bacchelli et al. 2001; Morgan et al. 2003), mutations in the homologous cis-regulatory elements may cause these malformations.

The positively identified cis-regulatory region 19.23 (Fig. 7A) activates transcription of unrelated genes in a promoter- and orientation-independent manner at large distances. These features are strikingly similar to the ones of a recently identified global control region (GCR), which regulates limb bud specific expression of $5^{\prime}$ Hoxd and the unrelated Evx2 and Lunapark (Lnp) genes (Spitz et al. 2003). Such GCRs seem to consist of multiple regulatory regions and/or enhancers that form a chromosomal regulatory landscape and act at a distance to coactivate sets of neighboring genes in specific tissues.
Comparison of the orthologous mouse and human genomic regions 19.23 reveals highly conserved sequences within introns (at least 100 bases with more than $75 \%$ identity) that are spread over the whole region (Fig. 7B). However, no obvious consensus binding sites for, for instance, GLI transcription factors have been found within these conserved blocks (F. Spitz, unpubl.).

Interestingly, neither Lnp nor Formin are essential for limb development in spite of these loci harboring the essential GCR and being expressed during limb bud development. Cis regulation of the further downstream 5'Hoxd and Gremlin genes by the GCR is however essential for distal limb bud morphogenesis (Zákány and Duboule 1996; Khokha et al. 2003; Michos et al. 2004). Experimental evidence indicates that the Formin landscape region 10.24 not only contains the regulatory elements necessary for activation, but also the ones mediating response to SHH signaling (Fig. 7A). Regulation of these two genes in the limb bud mesenchyme is likely regulated by interaction of several control regions scattered over the genomic landscape (Fig. 7A,B). Our studies also reveal for the first time that such landscapes and GCRs are not a peculiar feature of regulating function- 
ally related and clustered genes such as, for example, 5'Hoxd and globin genes (for review, see Zeller and Deschamps 2002). Rather, they seem to represent a novel mechanism by which tissue-specific coexpression of neighboring genes is orchestrated, even if they are structurally and functionally not related. These studies are likely to reveal the tip of the iceberg and further exploration of these regulatory landscapes will be necessary to understand if GCRs are composed of novel types of tissue-specific activator/enhancer elements or if they harbor elements enabling the known activators and enhancers to act over greater than usual distances (Fig. 7; Spitz et al. 2003). Last but not least, Shh expression in the limb bud mesenchyme is itself controlled by a regulatory region located $\sim 800 \mathrm{~kb}$ upstream within the unrelated Lmbr1 gene (Lettice et al. 2002).

It could well be that during evolution of vertebrates an initial selective constraint resulted in Formin and Grem- lin being kept neighboring genes and their expression became coregulated as part of a larger regulatory landscape. In fact, both genes are also expressed in similar but not identical patterns during kidney organogenesis, and genetic analysis has revealed essential functions for both genes during kidney development (Wynshaw-Boris et al. 1997; Michos et al. 2004). Initial intertwining of their regulation could have resulted in them becoming inseparably linked or trapped into this regulatory landscape, in spite of eventual diversification of their functions during vertebrate evolution. The present study establishes that Gremlin and Formin are neither part of the same pathway nor a common synexpression group (Niehrs and Pollet 1999), in spite of these two genes being coexpressed in various embryonic tissues. Much of the gene diversity during vertebrate evolution is thought to have arisen following gene and chromosomal duplications. Interestingly, the arrangement of Formin-2 (Leader
A

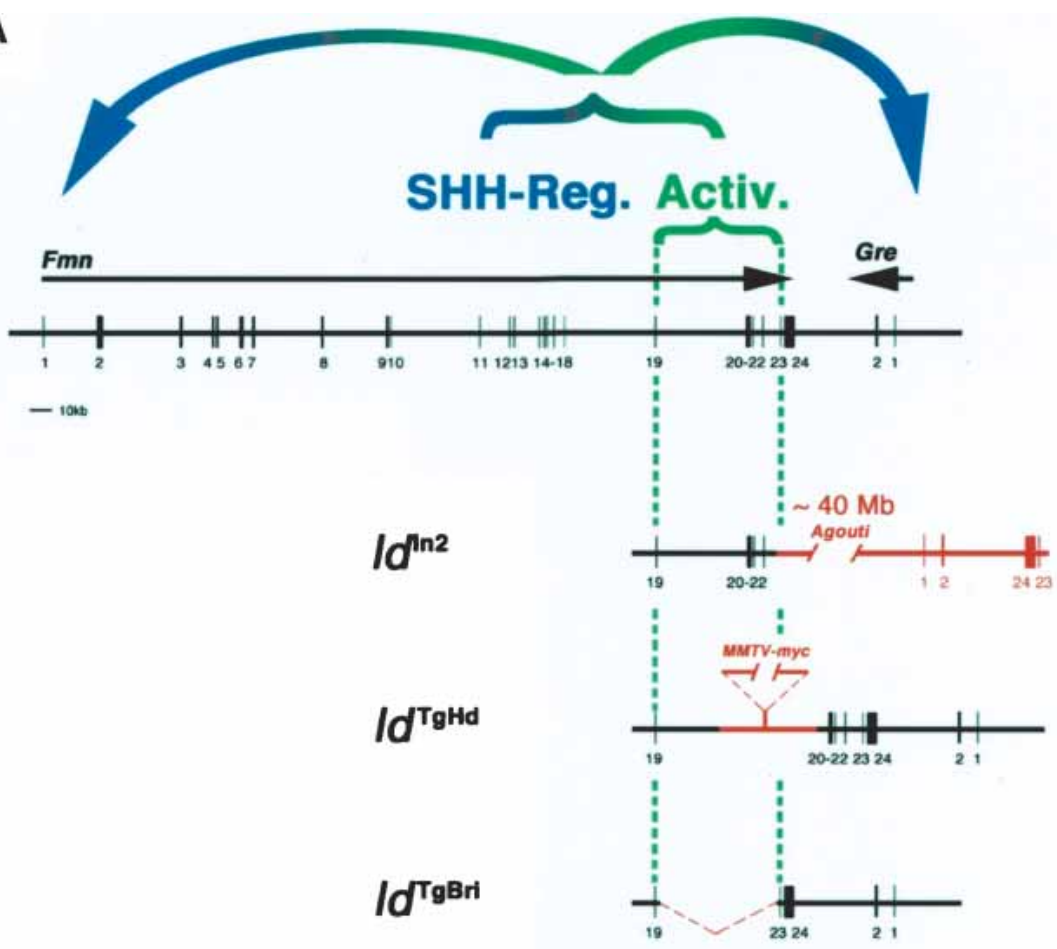

B

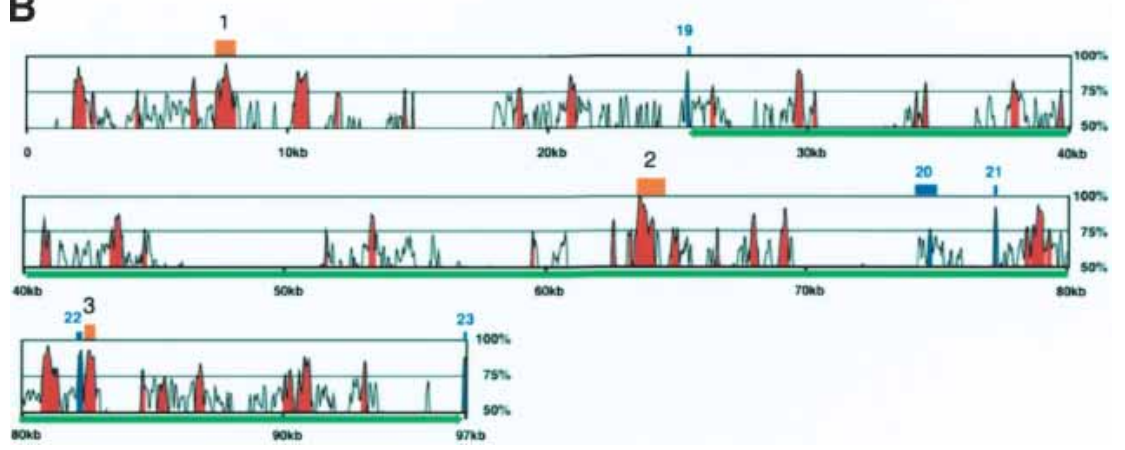

Figure 7. The large regulatory landscape required for activation of Gremlin expression in the limb bud mesenchyme. (A) Region 19.23 is disrupted by all relevant $1 d$ alleles. (Activ.) A global control region (GCR) located in the genomic region encompassing Formin exons 1923 is required in cis for activation of Gremlin and Formin expression in the posterior limb bud mesenchyme. This region is disrupted in the $1 d^{\text {In } 2}, l d^{\text {TgHd }}$, and $l d^{\text {TgBri }}$ alleles. (SHH-Reg.) The region necessary for $\mathrm{SHH}$-mediated regulation of Gremlin and Formin (see Fig. 5A-F) is most likely located upstream of Formin exon 19. Schemes show how the $l d^{\operatorname{In} 2}, l d^{\mathrm{TgHd}}$, and $1 d^{\mathrm{TgBri}}$ mutations disrupt the activator GCR. (B) Alignment of the orthologous region 19.23 from the mouse and human genome using the mVISTA program (window size, 100 bases; homology threshold, 65\%; Mayor et al. 2000). This alignment reveals multiple blocks of intronic sequences highly conserved between the two species. Exons 19-23 are indicated in blue and the parts of intronic sequences conserved more than $75 \%$ are marked as red peaks. The green line indicates the genomic sequences driving $\mathrm{LaCZ}$ expression in BAC construct C (see Fig. 6C). The chicken genomic region 19.23 is only partially available, with some gaps in the regions containing the blocks of sequence conserved between mouse and human genome that precluded complete analysis. However, three regions (indicated in orange) highly conserved among all three species have been identified. Region 1 (upstream of exon 19): $77.4 \%$ identity over 243 bases. Region 2 (upstream of exon 20): $85.1 \%$ over 329 bases. Region 3 (just downstream from exon 22): $81 \%$ over 352 bases. The human, mouse, and chicken genomic sequences were obtained from the Ensembl Genome Browser (http:// www.ensembl.org) using genome assembly releases v19.34b, v19.32.2, and prerelease1, respectively. 
and Leder 2000) and Gremlin-2 (or Prdc; Minabe-Saegusa et al. 1998) on mouse chromosome 1 is identical to chromosome 2, as the two genes are also located next to one another and transcribed in reverse orientation (see also UCSC Genome Browser, http://genome.ucsc.edu). During organogenesis, both Formin-2 and Gremlin-2 are expressed in the developing neural tube (Minabe-Saegusa et al. 1998; Leader and Leder 2000), suggesting that they could also be part of a common regulatory landscape.

Large-scale phenotypic screens have become a renewed and major effort to genetically analyze vertebrate model organisms such as zebrafish and mouse (Justice 2000). Such screens provide powerful tools to identify the gene cascades controlling development, physiology, and disease by scoring for the relevant phenotypes. However, the present study reveals that in specific cases, the identification and analysis of the essential gene and/or cascades can be rather tedious. The molecular alterations in the Formin locus together with the Formin transcript and protein distribution established this gene as the obvious candidate, whose disruption causes the $1 d$ phenotype (for reviews, see Zeller et al. 1999; Panman and Zeller 2003). Only the combination of experimental embryology with advanced reverse genetics and transgenesis has finally revealed the true nature of the $1 d$ limb phenotype and established Gremlin as the essential one of the two disrupted genes. As many vertebrate genes contain rather large intronic and noncoding regions, such large regulatory landscapes may be rather common and more surprises with respect to assigning phenotypes to alterations of particular genes and/or pathways may well be in store.

\section{Materials and methods}

\section{Mapping and identification of the $1 \mathrm{~d}^{\mathrm{OR}}$ and $\mathrm{ld}^{\mathrm{J}}$ mutations}

The deletion of the Gremlin ORF in the $1 d^{\mathrm{OR}}$ allele was initially detected by Southern blotting (Fig. 1B) and mapped using a combination of Southern blot and long-range PCR analysis (Jansen et al. 1997). A PCR fragment spanning the deletion breakpoints in the $l d^{\mathrm{OR}}$ allele was isolated. This fragment was sequenced and the extent of the deletion identified by sequence comparison to the wild-type Gremlin locus. The $1 d^{\mathrm{OR}}$ allele was crossed into 129S3/SvImJ, C57BL/6, and CD1 strains, as the penetrance of the kidney phenotype depends on genetic background. In the 129S and CD1 backgrounds, the kidney phenotype is fully penetrant (Supplementary Fig. 1). The point mutation affecting splicing of Gremlin in the $1 d^{\mathrm{J}}$ allele was identified as follows. Total RNAs were isolated from wild-type and $1 d^{\mathrm{J} / \mathrm{J}}$ mouse embryos (embryonic day 12 [E12]) using the RNeasy kit (Qiagen) and cDNAs synthesized using standard procedures. Gremlin transcripts were amplified using specific primers in exons 1 and 2. The Gremlin locus was analyzed comparing genomic DNA from wild-type and $1 d^{\mathrm{J} / \mathrm{J}}$ embryos. The genomic region containing the intron-exon 2 boundary was amplified by PCR and PCR products separated on a $1.0 \%$ agarose gel, and in all cases (cDNAs and genomic DNAs) only one specific fragment was amplified (data not shown). These amplified DNA bands were cloned and their sequences analyzed using the ClustalW-X program (http://www.ebi.ac.uk/clustalw). Sequences of all primers used for these studies are available upon request.

\section{Generation of Fmn mutant alleles}

The $F m n^{\Delta 10}$ allele was obtained by successive targeting in R1 ES cells (Nagy et al. 1993). Initially, Fmn exon 10 (151 bases) was completely replaced by a PGK-NeO ${ }^{\mathrm{R}}$ expression cassette with an SV40 polyadenylation site and a $\operatorname{Lox} P$ site was inserted further downstream in the intron (Fig. 2B). One of three correctly recombined ES-cell clones was selected for additional gene targeting. A PGK-Hygro ${ }^{\mathrm{R}}$ cassette flanked by two loxP sites and an En-2 splice acceptor-IRES-LacZ expression cassette (Mountford et al. 1994) was inserted into Fmn exon 24 using a Spe1 site 86 bases downstream of the translational stop codon. Fifty-three correctly targeted ES-cell clones were obtained and characterized extensively by genomic Southern blot analysis to confirm correct alterations of both targeted genomic sites. To identify clones carrying both targeting sites in cis, 25 ES-cell clones were electroporated with a Cre expression vector. For 14 ES-cell clones, the correct Cre-mediated excision patterns were obtained for all possible combinations between the three LoxP sites (Fig. 2B). ES-cell clones carrying the $F m n^{\Delta 10}$ allele were injected into C57BL/6 blastocysts and germ-line transmission was obtained. $F m n^{\Delta 10}$ mice were maintained by breeding a mixed 129xC57/BL6 background. The Fmn ${ }^{\Delta 10.24}$ allele was generated by intercrossing $F m^{\Delta 10 /+}$ mice with the Cre deleter mouse strain (Schwenk et al. 1995). PCR analysis was used to show that excision had occurred between the two most distant LoxP sites, causing deletion of the genomic region spanning Fmn exons 10-24 (170 kb).

\section{RT-PCR analysis of Formin expression}

Total RNA from wild-type, $F m n^{\Delta 10}$, and $F m n^{\Delta 10.24}$ homozygous embryos was isolated using the RNeasy extraction kit (Qiagen). First strand cDNAs were synthesized according to standard procedures by using $17 \mu \mathrm{g}$ of total RNA. Subsequently, PCR was performed to detect Formin transcripts. The following primer pairs were used: forward primer in exon 9 (e9, 5'GCTCTTCCTAACAGTGGAGGTCC-3') and reverse primer in exon $15($ e15, 5'-CACACTCTTCATGTGCAACAA-3') or exon 23 (e23L1, 5'-CTTTGTCTCCACTTTCTTCTCTGATG TC-3') for wild-type and $F m n^{\Delta 10 / \Delta 10}$ cDNAs, forward primer in exon 9 and reverse primer in IRES (IRES-1, 5'-GCTTCCTTC ACGACATTCAACAGACC-3') for $F m n^{\Delta 10.24 / \Delta 10.24}$ cDNAs. PCR products were separated on a $1.0 \%$ agarose gel and cloned for sequence analysis and alignment using the ClustalW-X program (http://www.ebi.ac.uk/clustalw).

Culture of mouse limb buds (trunk cultures) and inhibition of FGF signaling

Shh expressing cells were grafted into mouse limb buds (30-33 somites, E10.0-E10.25) cultured as described (Zuniga et al. 1999). Alternatively, FGF signaling was blocked by supplementing the culture medium with $10 \mu \mathrm{M}$ SU5402 (final concentration), an efficient inhibitor of FGF signal transduction (Mohammadi et al. 1997). SU5402 (Calbiochem) was dissolved in 100\% DMSO at $10 \mathrm{mg} / \mathrm{mL}$ (stock solution). Experimental controls were treated with an equal concentration of DMSO in culture medium (0.03\% final). The SU5402 concentration blocking FGF signaling efficiently was established in pilot experiments and is well within the commonly used range of concentrations. Both grafted and SU5402-treated limb buds were cultured for 14-16 h prior to analysis by in situ hybridization.

Skeletal preparations, whole mount in situ hybridization and LacZ staining

Skeletal preparations and whole mount in situ hybridization assays were carried out as previously described (Zuniga and 
Zeller 1999). $\beta$-Galactosidase (LacZ) activity was detected in whole mounts (Knittel et al. 1995) with the following modification: Embryos were stained in the dark at $37^{\circ} \mathrm{C}$ in $1 \mathrm{mg} / \mathrm{mL}$ $\mathrm{X}$-Gal, $0.25 \mathrm{mM} \mathrm{K}_{3} \mathrm{Fe}(\mathrm{CN})_{6}, 0.25 \mathrm{mM} \mathrm{K}_{4} \mathrm{Fe}(\mathrm{CN})_{6}, 0.01 \% \mathrm{NP} 40$, $0.4 \mathrm{mM} \mathrm{MgCl}{ }_{2}$ in $1 \times$ PBS.

\section{$B A C$ constructs and generation of transient transgenic} mouse embryos

The genomic organization of the Gremlin and Formin loci and the appropriate BACs were identified using sequences from the Mouse Genome Sequencing Consortium (Waterston et al. 2002) and analyzed with the UCSC Genome Browser (http:// genome.ucsc.edu). Mouse BAC clones were obtained from BacPac Resources (Children's Hospital Oakland, USA) and modified by ET recombination as described (Spitz et al. 2003). Construct A was engineered by inserting a $L a c Z$ reporter gene in frame into the Gremlin ORF encoded by BAC RP23-113H17 (Fig. 6A) using a Zeocin resistance cassette (Invitrogen). Construct $\mathrm{B}$ (Fig. 6B) was obtained by deleting the region between exons 19 and 23 from construct A using a Kanamycin resistance cassette. Construct C (Fig. 6C) was generated by targeted replacement of Fmn exon 23 and all downstream $3^{\prime}$ sequences from $\mathrm{BAC} 113 \mathrm{H} 17$ by a $\mathrm{LacZ}$ reporter gene driven by a $\beta$-globin minimal promoter (Spitz et al. 2003). This cassette is flanked by 50 bases of BAC DNA sequence, which borders the region to be deleted by homologous recombination. All BAC constructs were injected into the pronucleus of fertilized mouse eggs according to standard procedures (Spitz et al. 2001; Nagy et al. 2002) and embryos were collected during gestational day 10 (E10.5) and analyzed by LacZ staining.

\section{Acknowledgments}

We are grateful to H. Goedemans, N. Lagarde, and C. Lehmann for technical assistance and mouse husbandry, and to $\mathrm{K}$. $\mathrm{O}^{\prime}$ Leary for help in preparation of the manuscript. We are grateful to T. Kondo, M. Kmita, S.L. Ang, and F. Guillemot for providing targeting vectors, probes, and advice, and to A.M. van der Linden for advice in mapping and isolating the deletion breakpoints in the $1 d^{\mathrm{OR}}$ mutation. We thank J. Deschamps, F. Meijlink, I. Mattaj, D. Sussman, and C. Torres de los Reyes for helpful discussions and comments on the manuscript. This research was supported by the Faculty of Biology at Utrecht University, grants from the Dutch KNAW (to A.Z.) and NWO (to R.Z.), the Swiss National Science Foundation (to R.Z. and D.D.) and the two cantons of Basel (to R.Z).

The publication costs of this article were defrayed in part by payment of page charges. This article must therefore be hereby marked "advertisement" in accordance with 18 USC section 1734 solely to indicate this fact.

\section{References}

Avsian-Kretchmer, O. and Hsueh, A.J. 2003. Comparative genomic analysis of the eight-membered-ring cystine-knotcontaining bone morphogenetic protein (BMP) antagonists. Mol. Endocrinol. 18: 1-12.

Bacchelli, C., Goodman, F.R., Scambler, P.J., and Winter, R.M. 2001. Cenani-Lenz syndrome with renal hypoplasia is not linked to FORMIN or GREMLIN. Clin. Genet. 59: 203-205.

Chao, C.W., Chan, D.C., Kuo, A., and Leder, P. 1998. The mouse formin (Fmn) gene: Abundant circular RNA transcripts and gene-targeted deletion analysis. Mol. Med. 4: 614-628.

Evangelista, M., Zigmond, S., and Boone, C. 2003. Formins: Sig- naling effectors for assembly and polarization of actin filaments. J. Cell Sci. 116: 2603-2611.

Faustino, N.A. and Cooper, T.A. 2003. Pre-mRNA splicing and human disease. Genes \& Dev. 17: 419-437.

Gurrieri, F., Kjaer, K.W., Sangiorgi, E., and Neri, G. 2002. Limb anomalies: Developmental and evolutionary aspects. Am. J. Med. Genet. 115: 231-244.

Haramis, A.G., Brown, J.M., and Zeller, R. 1995. The limb deformity mutation disrupts the SHH/FGF-4 feedback loop and regulation of $5{ }^{\prime} \mathrm{HoxD}$ genes during limb pattern formation. Development 121: 4237-4245.

Jansen, G., Hazendonk, E., Thijssen, K.L., and Plasterk, R.H. 1997. Reverse genetics by chemical mutagenesis in Caenorhabditis elegans. Nat. Genet. 17: 119-121.

Justice, M.J. 2000. Capitalizing on large-scale mouse mutagenesis screens. Nat. Rev. Genet. 1: 109-115.

Khokha, M.K., Hsu, D., Brunet, L.J., Dionne, M.S., and Harland, R.M. 2003. Gremlin is the BMP antagonist required for maintenance of Shh and Fgf signals during limb patterning. Nat. Genet. 34: 303-307.

Knittel, T., Kessel, M., Kim, M.H., and Gruss, P. 1995. A conserved enhancer of the human and murine Hoxa-7 gene specifies the anterior boundary of expression during embryonal development. Development 121: 1077-1088.

Kobielak, A., Pasolli, H.A., and Fuchs, E. 2004. Mammalian formin-1 participates in adherens junctions and polymerization of linear actin cables. Nat. Cell Biol. 6: 21-30.

Leader, B. and Leder, P. 2000. Formin-2, a novel formin homology protein of the cappuccino subfamily, is highly expressed in the developing and adult central nervous system. Mech. Dev. 93: 221-231.

Lettice, L.A., Horikoshi, T., Heaney, S.J., Van Baren, M.J., Van Der Linde, H.C., Breedveld, G.J., Joosse, M., Akarsu, N., Oostra, B.A., Endo, N., et al. 2002. Disruption of a long-range cis-acting regulator for Shh causes preaxial polydactyly. Proc. Nat1. Acad. Sci. 99: 7548-7553.

Maas, R.L., Zeller, R., Woychik, R.P., Vogt, T.F., and Leder, P. 1990. Disruption of formin-encoding transcripts in two mutant limb deformity alleles. Nature 346: 853-855.

Maas, R.L., Jepeal, L.I., Elfering, S.L., Holcombe, R.F., Morton, C.C., Eddy, R.L., Byers, M.G., Shows, T.B., and Leder, P. 1991. A human gene homologous to the formin gene residing at the murine limb deformity locus: Chromosomal location and RFLPs. Am. J. Hum. Genet. 48: 687-695.

Maas, R., Elfering, S., Glaser, T., and Jepeal, L. 1994. Deficient outgrowth of the ureteric bud underlies the renal agenesis phenotype in mice manifesting the limb deformity (ld) mutation. Dev. Dyn. 199: 214-228.

Mayor, C., Brudno, M., Schwartz, J.R., Poliakov, A., Rubin, E.M., Frazer, K.A., Pachter, L.S., and Dubchak, I. 2000. VISTA: Visualizing global DNA sequence alignments of arbitrary length. Bioinformatics 16: 1046-1047.

Merino, R., Rodriguez-Leon, J., Macias, D., Ganan, Y., Economides, A.N., and Hurle, J.M. 1999. The BMP antagonist Gremlin regulates outgrowth, chondrogenesis and programmed cell death in the developing limb. Development 126: 5515-5522.

Michos, O., Panman, L., Vintersten, K., Beier, K., Zeller, R., and Zuniga, A. 2004. Gremlin mediated BMP antagonism induces the epithelial-mesenchymal feedback signaling controlling metanephric kidney and limb organogenesis. Development (in press).

Minabe-Saegusa, C., Saegusa, H., Tsukahara, M., and Noguchi, S. 1998. Sequence and expression of a novel mouse gene PRDC (protein related to DAN and cerberus) identified by a gene trap approach. Dev. Growth Differ. 40: 343-353. 
Mohammadi, M., McMahon, G., Sun, L., Tang, C., Hirth, P., Yeh, B.K., Hubbard, S.R., and Schlessinger, J. 1997. Structures of the tyrosine kinase domain of fibroblast growth factor receptor in complex with inhibitors. Science 276: 955960.

Morgan, B.A., Conlon, F.L., Manzanares, M., Millar, J.B., Kanuga, N., Sharpe, J., Krumlauf, R., Smith, J.C., and Sedgwick, S.G. 1996. Transposon tools for recombinant DNA manipulation: Characterization of transcriptional regulators from yeast, Xenopus, and mouse. Proc. Natl. Acad. Sci. 93: 28012806.

Morgan, N.V., Bacchelli, C., Gissen, P., Morton, J., Ferrero, G.B., Silengo, M., Labrune, P., Casteels, I., Hall, C., Cox, P., et al. 2003. A locus for asphyxiating thoracic dystrophy, ATD, maps to chromosome 15q13. J. Med. Genet. 40: 431-435.

Mountford, P., Zevnik, B., Duwel, A., Nichols, J., Li, M., Dani, C., Robertson, M., Chambers, I., and Smith, A. 1994. Dicistronic targeting constructs: Reporters and modifiers of mammalian gene expression. Proc. Natl. Acad. Sci. 91: 43034307.

Nagy, A., Rossant, J., Nagy, R., Abramow-Newerly, W., and Roder, J.C. 1993. Viable cell culture-derived mice from early passage embryonic stem cells. Proc. Natl. Acad. Sci. 90: 8424-8428.

Nagy, A., Gertsensten, M., Vintersten, K., and Behringer, R. 2002. Manipulating the mouse embryo: A laboratory manual. Cold Spring Harbor Press, Cold Spring Harbor, New York.

Niehrs, C. and Pollet, N. 1999. Synexpression groups in eukaryotes. Nature 402: 483-487.

Panman, L. and Zeller, R. 2003. Patterning the limb before and after SHH signalling. J. Anat. 202: 3-12.

Perkins, A.S. 2002. Functional genomics in the mouse. Funct. Integr. Genomics 2: 81-91.

Schwenk, F., Baron, U., and Rajewsky, K. 1995. A cre-transgenic mouse strain for the ubiquitous deletion of loxP-flanked gene segments including deletion in germ cells. Nucleic Acids Res. 23: 5080-5081.

Spitz, F., Gonzalez, F., Peichel, C., Vogt, T.F., Duboule, D., and Zakany, J. 2001. Large scale transgenic and cluster deletion analysis of the HoxD complex separate an ancestral regulatory module from evolutionary innovations. Genes \& Dev. 15: 2209-2214.

Spitz, F., Gonzalez, F., and Duboule, D. 2003. A global control region defines a chromosomal regulatory landscape containing the HoxD cluster. Cell 113: 405-417.

Sun, X., Mariani, F.V., and Martin, G.R. 2002. Functions of FGF signalling from the apical ectodermal ridge in limb development. Nature 418: 501-508.

Vogt, T.F., Jackson Grusby, L., Wynshaw Boris, A.J., Chan, D.C., and Leder, P. 1992. The same genomic region is disrupted in two transgene-induced limb deformity alleles. Mamm. Genome 3: 431-437.

Wang, C.C., Chan, D.C., and Leder, P. 1997. The mouse formin (Fmn) gene: Genomic structure, novel exons, and genetic mapping. Genomics 39: 303-311.

Waterston, R.H., Lindblad-Toh, K., Birney, E., Rogers, J., Abril, J.F., Agarwal, P., Agarwala, R., Ainscough, R., Alexandersson, M., An, P., et al. 2002. Initial sequencing and comparative analysis of the mouse genome. Nature 420: 520-562.

Woychik, R.P., Stewart, T.A., Davis, L.G., D'Eustachio, P. and Leder, P. 1985. An inherited limb deformity created by insertional mutagenesis in a transgenic mouse. Nature 318: 36-40.

Woychik, R.P., Generoso, W.M., Russell, L.B., Cain, K.T., Cacheiro, N.L.A., Bultman, S.J., Selby, P.B., Dickinson, M.E.,
Hogan, B.L.M., and Rutledge, J.C. 1990. Molecular and genetic characterisation of a radiation-induced structural rearrangement in mouse chromosome 2 causing mutations at the limb deformity and agouti loci. Proc. Natl. Acad. Sci. 87: 2588-2592.

Wynshaw-Boris, A., Ryan, G., Deng, C.X., Chan, D.C., JacksonGrusby, L., Larson, D., Dunmore, J.H., and Leder, P. 1997. The role of a single formin isoform in the limb and renal phenotypes of limb deformity. Mol. Med. 3: 372-384.

Zákány, J. and Duboule, D. 1996. Synpolydactyly in mice with a targeted deficiency in the HoxD complex. Nature 384: 6971.

Zeller, R. and Deschamps, J. 2002. Developmental biology: First come, first served. Nature 420: 138-139.

Zeller, R., Haramis, A., Zuniga, A., McGuigan, C., Dono, R., Davidson, G., Chabanis, S., and Gibson, T. 1999. Formin defines a large family of morphoregulatory genes and functions in establishment of the polarising region. Cell Tissue Res. 296: 85-93.

Zuniga, A. and Zeller, R. 1999. Gli3 (Xt) and formin (ld) participate in the positioning of the polarising region and control of posterior limb-bud identity. Development 126: 13-21.

Zuniga, A., Haramis, A.P., McMahon, A.P., and Zeller, R. 1999. Signal relay by BMP antagonism controls the SHH/FGF4 feedback loop in vertebrate limb buds. Nature 401: 598-602. 


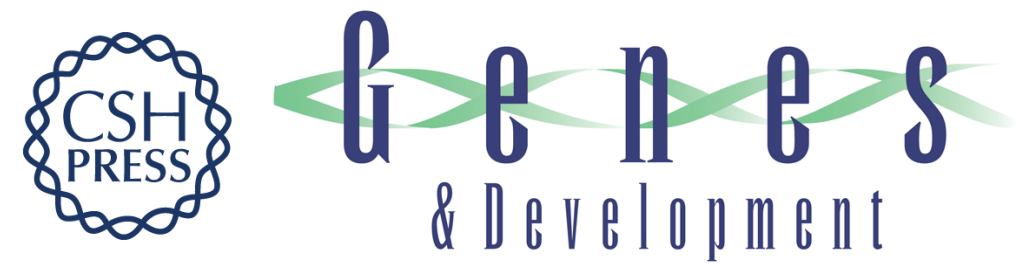

\section{Mouse limb deformity mutations disrupt a global control region within the large regulatory landscape required for Gremlin expression}

Aimée Zuniga, Odyssé Michos, François Spitz, et al.

Genes Dev. 2004, 18:

Access the most recent version at doi:10.1101/gad.299904

Supplemental http://genesdev.cshlp.org/content/suppl/2004/06/16/299904.DC1
Material

References This article cites 42 articles, 14 of which can be accessed free at:

http://genesdev.cshlp.org/content/18/13/1553.full.html\#ref-list-1

License

Email Alerting

Receive free email alerts when new articles cite this article - sign up in the box at the top

Service

right corner of the article or click here.

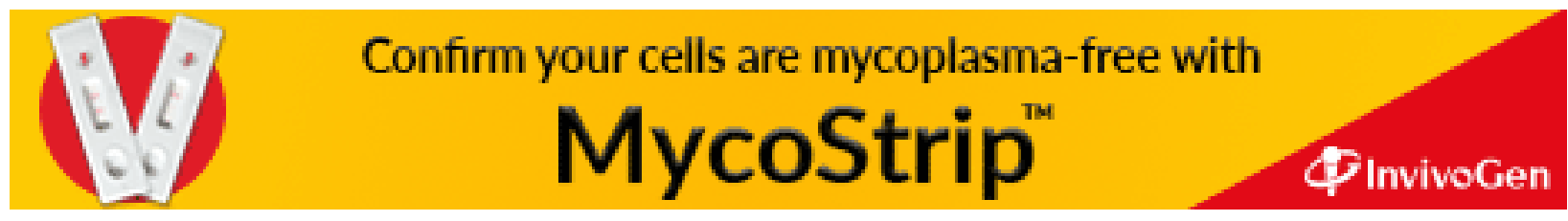

